\title{
MODELLING OF HEAT GENERATION IN AN 18650 LITHIUM-ION BATTERY CELL UNDER VARYING DISCHARGE RATES Foo Shen Hwang ${ }^{1 *}$, Thomas Confrey ${ }^{1}$, Stephen Scully ${ }^{1}$, Dean Callaghan ${ }^{1}$, Cathal Nolan ${ }^{1}$, Nigel Kent ${ }^{1}$, Barry Flannery ${ }^{2}$
}

\author{
${ }^{1}$ Department of Engineering, Institute of Technology Carlow, Ireland \\ ${ }^{2}$ Xerotech Limited, Ireland
}

\begin{abstract}
Thermal characterization plays an important role in battery pack design. Lithium-ion batteries have to be maintained between $15-35{ }^{\circ} \mathrm{C}$ to operate optimally. Heat is generated (Q) internally within the batteries during both the charging and discharging phases. This can be quantified using several standard methods. The most common method, factors both the joule heating effects and the entropic changes across the battery. In addition, such values can be derived by identifying the open circuit voltage (OCV), nominal voltage $(\mathrm{V})$, operating current $(\mathrm{I})$, battery temperature $(\mathrm{T})$ and the rate of change of the open circuit voltage in relation to temperature $(\mathrm{dOCV} / \mathrm{dT})$. This paper focuses on experimental characterization and comparative modelling of the heat generation rate $(Q)$ across several current discharge rates $(0.5 \mathrm{C}, 1 \mathrm{C}$ and $1.5 \mathrm{C})$ of an 18650 cell. Analysis is conducted utilizing several non-linear mathematical functions methods including polynomial, exponential, and power models. Parameter fitting is carried out over the respective function orders; polynomial $(n=3 \sim 7)$, exponential $(n=2)$ and power function. The generated parameter fitting functions are then used as heat source functions in a 3D computational fluid dynamics (CFD) solver under natural convection conditions. Generated temperature profiles are analyzed for errors based on experimental discharge tests, conducted at standard room temperature $\left(25^{\circ} \mathrm{C}\right)$. Initial experimental results display low deviation between both experimental and CFD temperature plots. As such, the heat generation function formulated could be easier utilized for larger battery applications than other methods available.
\end{abstract}

KEYWORDS: Lithium-ion battery; Voltage drop; Curve fitting; Computational fluid dynamics (CFD)

\section{INTRODUCTION}

With the advent of electric vehicles into the automotive market, there has been an increasing need to improve the efficiency of the vehicle's battery. The rechargeable lithium-ion batteries deployed in the majority of such vehicles are advantageous compared to other battery types due to their high energy densities and high specific energies [1]. However, such batteries are heavily influenced by their operating temperatures. High temperatures could potentially cause thermal runaway [2] while low temperatures would cause capacity fade and reduction in ionic reaction [3]. Thus, accurate modelling of the heat generation rate of such batteries is required in the design process of the on-board thermal management system.

Works done by Newman and Tiedemann, Bernardi, Chen and Evans, Al-Hallaj, Evan and White have established much of the foundational knowledge of battery heat generation [4-8]. A majority of the works done by the aforementioned research groups acknowledges that the heat generation rate of the battery would primarily comprise of both Joule heating and reversible heat generation effect as displayed in Eq. (1)

$$
Q=I\left[(O C V-V)-\left(T_{b a t} \frac{d O C V}{d T}\right)\right] .
$$


Whereby the first group of values describes the irreversible Joule heating effects and the second the reversible entropic heat produced by the battery. Apart from the discharge current, the variables across Eq. (1) vary transiently depending on the state of charge (SOC) of the battery.

While there are numerous equations that generalize the heat generated by the battery, not many have formulated a curve-characterization function of the heat generated. Gümüşsu et al. and Catherino analysed the heat generation $(\mathrm{Q})$ of a cylindrical and prismatic lithium ion battery respectively at varying discharge rates with respect to time but had not stated any functions $[9,10]$. It could be assumed that this was not done for their papers intended that the reader inputs their own power profile based on their load type. Nevertheless, formulation of such a function would be required in approximating li-ion battery temperature rises.

\section{METHODOLOGY}

\subsection{Lithium-Ion Heat Generation Model}

Within this study, the heat generation of a NCR18650B battery is modelled. The heat generation plot described by Gümüssu et. al. was used as a reference in determining the heat generation equation [9]. Firstly, the heat generation values of the battery at $1 \mathrm{C}$ discharge was modelled through a polynomial, exponential and power equation with the mathematical software, Origin2019B. Derived functions are used as a transient heat source under a natural convection CFD model. Transient temperature gains of the battery are then compared with literature. The function with the least deviation is then used for the other $0.5 \mathrm{C}$ and $1.5 \mathrm{C}$ discharge rates.

2.1.1 Polynomial function. Considering the practicality and scalability of a polynomial function, it may be adapted to represent the intricacies of the battery heat generation model. The polynomial equation is represented as,

$$
Q=a_{0}+a_{1} t+a_{2} t^{2}+\ldots+a_{n} t^{n}
$$

Where $\boldsymbol{a}_{\mathbf{0}} \sim \boldsymbol{a}_{\boldsymbol{n}}$ are coefficients corresponding to the polynomial fitting method, $\mathbf{Q}\left(\mathrm{W} / \mathrm{m}^{3}\right)$ is the heat generation rate and $\mathbf{t}(\mathrm{sec})$ is the time passed.

2.1.2 Exponential function. A notable characteristic of the battery's heat generation as it approaches 0 $\mathrm{SoC}$ is its exponentially large increase in heat. Thus, it may be practical to fit the heat generation function through an exponential equation as shown in Eq. 3,

$$
Q=Q_{o}+a_{1} e^{t / b_{1}}+a_{2} e^{t / b_{2}} .
$$

Where $\boldsymbol{Q}_{\mathbf{0}}\left(\mathrm{W} / \mathrm{m}^{3}\right)$ is the initial heat generation, $\boldsymbol{a}_{\mathbf{1}}, \boldsymbol{a}_{\mathbf{2}}, \boldsymbol{b}_{\mathbf{1}}$ and $\boldsymbol{b}_{\mathbf{2}}$ are coefficients corresponding to the exponential model, and $\mathbf{t}(\mathrm{sec})$ is the time passed. It should be noted that $\boldsymbol{Q}_{\mathbf{0}}$ varies according to both the C-rate and capacity of the battery.

2.1.3 Power function. Similar to that of an exponential function, power functions hold similar characteristics whereby they are able to match the notable rise in heat generation towards the end of the discharge cycle. The power function may be represented as follows;

$$
Q=Q_{o}+a_{1}|t-t c|^{p}
$$

Where $\boldsymbol{Q}_{\mathbf{0}}\left(\mathrm{W} / \mathrm{m}^{3}\right)$ is the initial heat generation, $\boldsymbol{a}_{\mathbf{1}}, \boldsymbol{t} \boldsymbol{c}$ and $\boldsymbol{p}$ are coefficients corresponding to the power model, and $\mathbf{t}(\mathrm{sec})$ is the time passed. 
2.1.4 Root mean square error. To determine the accuracy of the heat generation model, the equation formulated is introduced as a heat source function of the CFD model under the presets described in section 2.1.5. The maximum temperature generated by the CFD model is then compared with temperature rise values obtained in literature. There are several statistical means of determining data accuracy including the Mean Absolute Error (MAE), Mean Absolute Percentage Error (MAPE) and Root Mean Square Error (RMSE) methods. The practicality of each are debated in numeral studies whereby some such as Willmott and Matsuura [11] state that the MAE method is a better metric for measuring average error while Chai and Draxler [12] highlights that the RMSE method is appropriate for highlighting error distribution in statistical data due to its sensitivity to maximum and minimum errors. Thus, the RMSE method was used as the method allows error values to be more quantitively pronounced [9]. The formula is written as such,

$$
R M S E=\sqrt{\frac{1}{n} \sum\left(T_{C F D}-T_{l i t}\right)^{2} .}
$$

Whereby, $T_{C F D}$ are CFD generated temperatures, $T_{l i t}$ are literature temperatures and $n$ is the number of values compared.

2.1.5 CFD settings. The preset settings for the CFD simulation included a heat transfer coefficient of $10 \mathrm{~W} / \mathrm{m}^{2} \mathrm{~K}$ and a free stream temperature of $25^{\circ} \mathrm{C}$ to mimic standard room conditions under natural convection. Thermophysical properties of the battery are based of literature values and are described within Table $1[7,9,13,14]$.

Table 1 Battery thermophysical properties

\begin{tabular}{c|c}
\hline \hline Thermophysical properties & Battery \\
\hline$\rho\left(k g / \mathrm{m}^{3}\right)$ & 2939 \\
\hline$c_{p}(J / k g K)$ & 2400 \\
\hline$k(W / m K)$ & 3 \\
\hline \hline
\end{tabular}

With the intent of ensuring mesh reliability and accuracy, a grid independence study was conducted as displayed in Fig. 1. It was noted that the increase in the number of cells did not alter the temperature rise of the battery at any significance. Hence, mesh 1 was used as it required the least amount of computational power while maintaining relevant results.

(a)

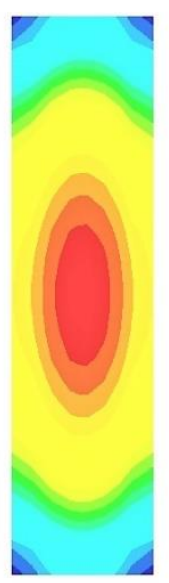

(b)

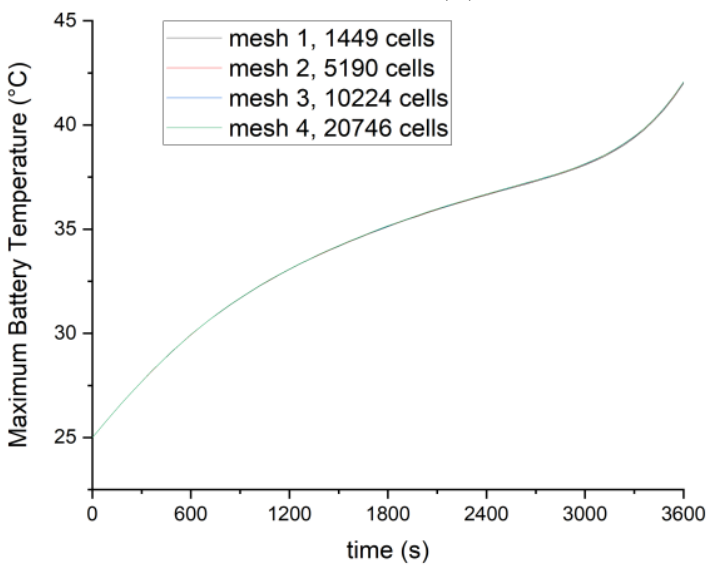

Fig. 1 (a) Battery model temperature distribution at $t=3600$ s (b) CFD grid independence, discharge rate $=1.0 \mathrm{C}$ 
Upon achieving grid convergence, the heat generation equation function was implemented into a userdefined function (UDF) and in the CFD module within the ANSYS software. The CFD simulation was set to run at 3600 time-steps to mimic a one-hour discharge test at 1000 iterations each. Temperature values obtained are then compared with literature values.

\section{RESULTS AND DISCUSSION}

\subsection{Heat generation function}

The heat generation functions were determined through the mathematical software Origin 2019b. A function is deemed fitted when the R-square value is approximately 0.9 indicating sufficient accuracy of the function.

3.1.1 Polynomial function. The various polynomial functions are compared against heat generation values obtained in literature [9] as shown in Fig. 2 below. It is presumed that the increase in polynomial number should increase the accuracy of the results obtained.

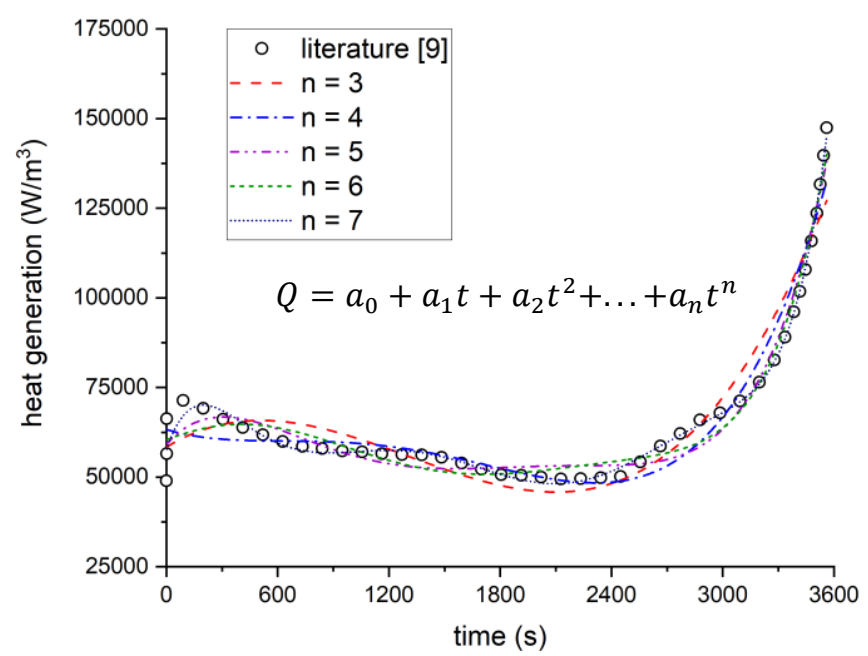

Fig. 2 Polynomial eq. (2) heat generation values at 1C discharge

Coefficient parameter values of the polynomial functions are tabulated below as seen in Table 3. Such values may be used for the heat generation function of a battery discharging at $1 \mathrm{C}$.

Table 3 Coefficient values for the polynomial heat generation values

\begin{tabular}{ccccccccc}
\hline \hline $\mathrm{N}$ & $\mathrm{a} 0$ & $\mathrm{a} 1$ & $\mathrm{a} 2$ & $\mathrm{a} 3$ & $\mathrm{a} 4$ & $\mathrm{a} 5$ & $\mathrm{a} 6$ & $\mathrm{a} 7$ \\
\hline \hline 7 & 57681.939 & 152.022 & -0.616 & $9.682 \mathrm{E}-4$ & $-7.580 \mathrm{E}-7$ & $3.121 \mathrm{E}-10$ & $-6.460 \mathrm{E}-14$ & $5.308 \mathrm{E}-18$ \\
6 & 60406.184 & 19.158 & -0.010 & $-4.248 \mathrm{E}-5$ & $4.463 \mathrm{E}-8$ & $-1.572 \mathrm{E}-11$ & $1.903 \mathrm{E}-15$ & - \\
5 & 59116.312 & 58.028 & -0.138 & $1.102 \mathrm{E}-4$ & $-3.751 \mathrm{E}-8$ & $4.683 \mathrm{E}-12$ & - & - \\
4 & 63287.735 & -15.664 & 0.028 & $-1.993 \mathrm{E}-5$ & $4.194 \mathrm{E}-9$ & - & - & - \\
3 & 58349.228 & 31.836 & -0.039 & $9.921 \mathrm{E}-6$ & - & - & - & - \\
\hline \hline
\end{tabular}

3.1.2 Exponential function. Figure 3 displays the exponential function for the heat generation curve. While the function is able to capture the general shape of the referenced heat generation, it is not able to match the minor peaks and trough during the beginning of the discharge process. 


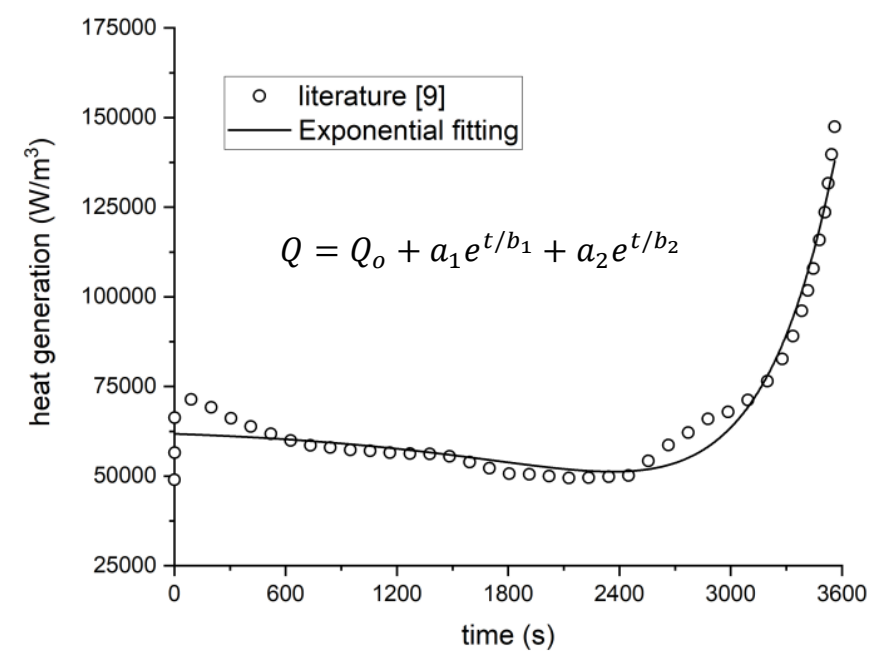

Fig. 3 Exponential heat generation eq. (3) values at $1 \mathrm{C}$ discharge

Coefficient values for the function are displayed in Table 4. Like the coefficients in Table 3, the values may be used for the heat source equation of a typical li-ion cell.

Table 4 Exponential coefficient values

\begin{tabular}{ccccc}
\hline \hline Q0 & a1 & b1 & a2 & b2 \\
\hline 63518.402 & 104.63607 & 478.017 & -1833.720 & 879.116 \\
\hline \hline
\end{tabular}

3.1.3 Power function. Fig. 4 displays the power law function of the heat generation equation. Like the exponential function model presented in Section 3.2, the function is able to capture the general shape of the referenced heat generation. The only notable difference is the stabilization of heat generation during the nominal voltage period of the battery. Table 5 displays the coefficient values of the power function formula.

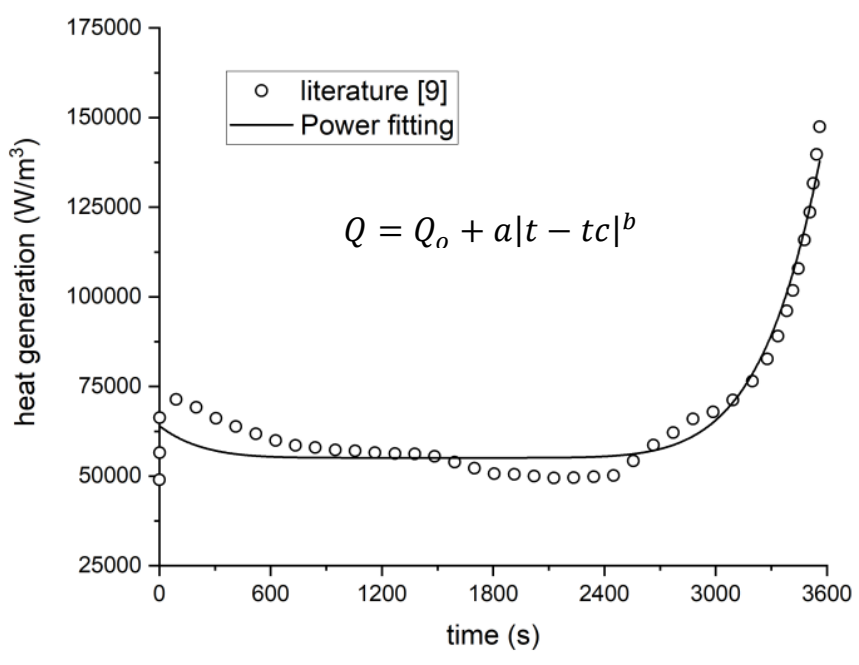

Fig. 4 Power heat generation values at $1 \mathrm{C}$ discharge

Table 5 Power function coefficient values

\begin{tabular}{cccc}
\hline \hline Q0 & $\mathrm{a}$ & tc & $\mathrm{b}$ \\
\hline 55107.379 & $1.151 \mathrm{E}-17$ & 1481.839 & 6.588 \\
\hline \hline
\end{tabular}




\subsection{RMSE values}

The heat generation functions are applied as UDF's in the CFD model as shown within Figure 1. Maximum temperature readings are measured for variance based of literature values through the RMSE method as displayed in Figure 5. Through the RMSE method, it was noted that the variance in output temperature values at $1 \mathrm{C}$ discharge varied from $1.532^{\circ} \mathrm{C}$ to $1.879^{\circ} \mathrm{C}$. While the initial presumption was that the increase in polynomial number would increase the accuracy of the results, it was observed that the RSME value did not linearly decrease with the increase in polynomial number. Such results could be correlated to the fact that the Bernardi heat generation equation was meant as a rough estimate of battery heat generation. With the experimental temperature measured by Gümüssu et. al. being done along the surface of the battery [9] and the maximum temperature measured by CFD done from the center of the battery, such would result in an amalgamation of errors that would prevent one from truly acquiring a perfect function. Furthermore, the RSME methodology accounts for general variances. The exponential and power generation functions had low variances during the middle of the cycle but had higher at both the beginning and end of the cycle. Thus, such results might not affect the true accuracy of the functions. Nevertheless, such error margins may be considered relatively low as Gümüssu et. al. reportedly had error margins of up to $3^{\circ} \mathrm{C}$ across their varying discharge tests [9]. Reportedly, the $7^{\text {th }}$ order polynomial function has the lowest RMSE value of $1.532^{\circ} \mathrm{C}$ and was used for the others.

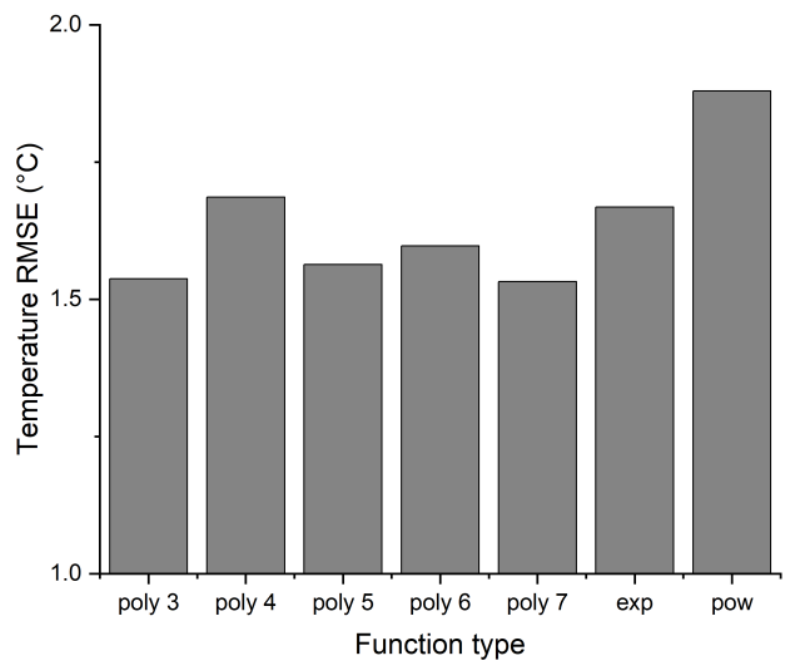

Fig. 5 Comparison of the RMSE values across the various function types at 1C Discharge

\subsection{CFD Results}

The mathematical function is modelled for the remaining discharge rates as displayed in Figure 6 below. It is noticed that the troughs at lower discharge rates are less pronounced as those of higher discharge rates. Such characteristics match that of heat generation rates in literature as observed by the drop in heat generation values as the battery approaches its nominal capacity and the exponential rise in heat generation as it reaches the end of the discharge cycle highlighting the large difference between the open circuit voltage and the nominal voltage [15]. Coefficient values of the function are displayed in Table 6. 


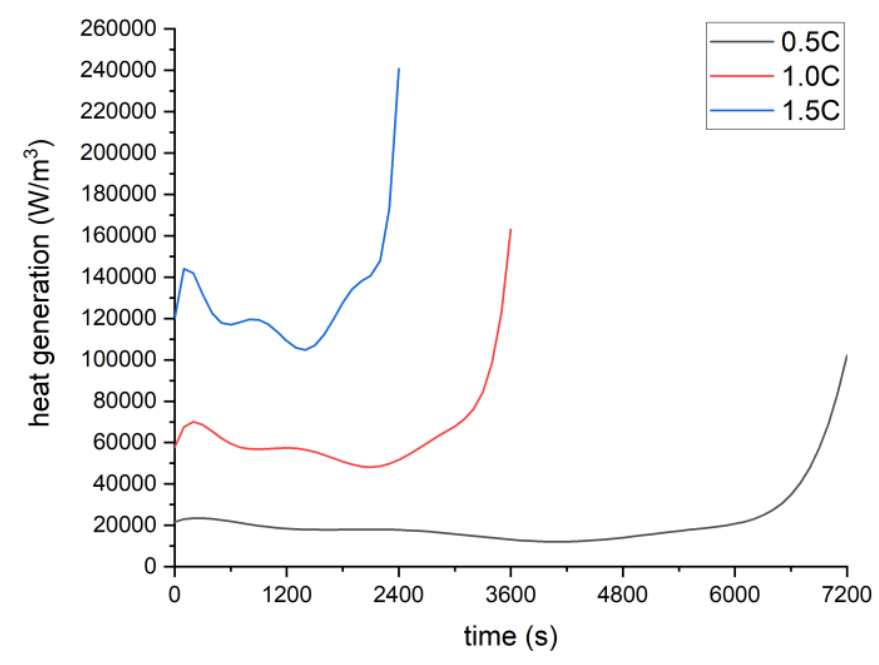

Fig. 6 Seventh order polynomial function heat generation values

Table 6 Polynomial function coefficients

\begin{tabular}{ccccccccc}
\hline $\begin{array}{c}\text { Discharge } \\
\text { rate }\end{array}$ & $\mathrm{a} 0$ & $\mathrm{a} 1$ & $\mathrm{a} 2$ & $\mathrm{a} 3$ & $\mathrm{a} 4$ & $\mathrm{a} 5$ & $\mathrm{a} 6$ & $\mathrm{a} 7$ \\
\hline \hline $0.5 \mathrm{C}$ & 21712.102 & 16.878 & -0.048 & $4.387 \mathrm{E}-5$ & $-1.914 \mathrm{E}-8$ & $4.289 \mathrm{E}-12$ & $-4.765 \mathrm{E}-16$ & $2.084 \mathrm{E}-20$ \\
$1.0 \mathrm{C}$ & 57681.939 & 152.023 & -0.616 & $9.682 \mathrm{E}-4$ & $-7.580 \mathrm{E}-7$ & $3.121 \mathrm{E}-10$ & $-6.460 \mathrm{E}-14$ & $5.308 \mathrm{E}-18$ \\
$1.5 \mathrm{C}$ & 119986.993 & 465.104 & -2.836 & 0.007 & $-7.732 \mathrm{E}-6$ & $4.723 \mathrm{E}-9$ & $-1.449 \mathrm{E}-12$ & $1.760 \mathrm{E}-16$ \\
\hline \hline
\end{tabular}

Upon determining the heat generation functions, they were used as input into the CFD model and its results are compared with literature values as highlighted in Figure 7. There is a good fit amongst the $0.5 \mathrm{C}$ and $1.0 \mathrm{C}$ discharge temperature values however the $1.5 \mathrm{C}$ discharge values appear to deviate to a greater extent.

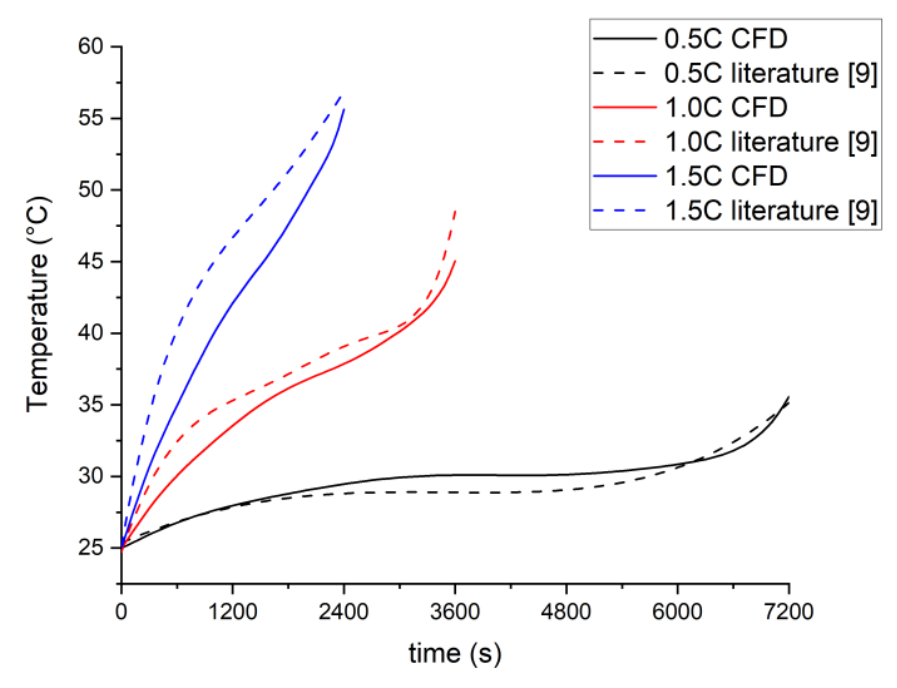

Fig. 7 Polynomial function against Gümüssu et. al. values [9]

Quantitatively, the RMSE fitting described in Fig. 8 show that the 1.5C discharge polynomial function has an error range that is less than $4^{\circ} \mathrm{C}$ which is similar to results obtained within literature [9]. Such values would indicate a lack of accuracy of the function towards higher discharge rates. As such, the equation formulated should be used cautiously beyond a $1 \mathrm{C}$ discharge rate. 


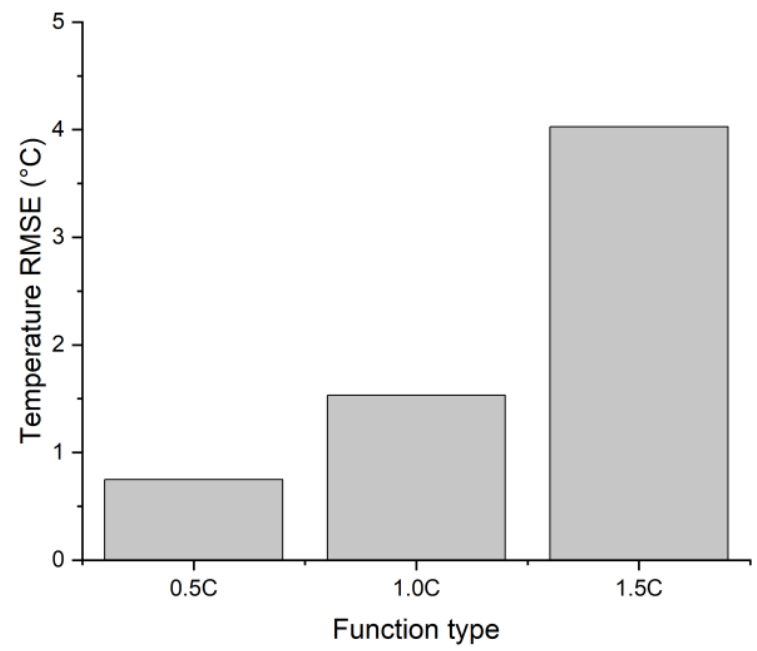

Fig. $7 \mathrm{RMSE}$ values of the other heat generation equation at $0.5 \mathrm{C}, 1.0 \mathrm{C}$ and $1.5 \mathrm{C}$ discharge

\section{CONCLUSION}

The heat generation function of an NCR 18650B lithium ion battery was mathematically fitted through various function fitting methods including polynomial, exponential and power fitting methods. The fitted heat generation functions were then utilized as a heat source within a CFD model and its temperature output compared with literature values, firstly at a discharge rate of $1 \mathrm{C}$. Through the results obtained, it was noted that the seventh order polynomial function had the best fit amongst the other function types and was then used to further model other discharge values.

It was observed that the temperature output of the polynomial function had low RMSE values at $0.5 \mathrm{C}$ discharge but had significantly higher values at $1.5 \mathrm{C}$ discharge. As such, the heat generation function formulated should be used with discretion. Reliability of the fitted models at higher discharge rates may be improved by increasing the factor of safety of the model at higher discharge rates. Nevertheless, better modelling techniques are constantly being generated and such functions may be used to better improve future battery thermal management technologies.

\section{NOMENCLATURE}

$\begin{array}{ll}c_{p} & \text { specific heat capacity } \\ I & \text { current } \\ k & \text { thermal conductivity } \\ \text { OCV } & \text { open circuit voltage } \\ \rho & \text { density }\end{array}$

$\begin{array}{cll}(\mathrm{J} / \mathrm{kg} \mathrm{K}) & \mathrm{Q} & \text { heat generation } \\ (\mathrm{A}) & \mathrm{T} & \text { temperature } \\ (\mathrm{W} / \mathrm{mK}) & \text { tc } & \text { time constant } \\ (\mathrm{V}) & V & \text { voltage } \\ \left(\mathrm{kg} / \mathrm{m}^{3}\right) & v_{a} & \text { ambient velocity }\end{array}$

\section{REFERENCES}

[1] M. Brian, Types of Batteries Used for Electric Vehicles, (n.d.). http://large.stanford.edu/courses/2016/ph240/mok2/ (accessed September 14, 2018).

[2] X. Feng, M. Ouyang, X. Liu, L. Lu, Y. Xia, X. He, Thermal runaway mechanism of lithium ion battery for electric vehicles: A review, Energy Storage Mater. 10 (2017). doi:10.1016/j.ensm.2017.05.013.

[3] A. Senyshyn, M.J. Mühlbauer, O. Dolotko, H. Ehrenberg, Low-temperature performance of Li-ion batteries: The behavior of lithiated graphite, J. Power Sources. 282 (2015) 235-240. doi:10.1016/j.jpowsour.2015.02.008.

[4] D. Bernardi, E. Pawlikowski, J. Newman, A General Energy Balance for Battery Systems, 1985. doi:10.1149/1.2113792. 
[5] Y. Chen, J. W. Evans, Heat Transfer Phenomena in Lithium/Polymer-Electrolyte Batteries for Electric Vehicle Application, J. Electrochem. Soc. - J ELECTROCHEM SOC. 140 (1993) 1833-1837. doi:10.1149/1.2220724.

[6] J. Newman, W. Tiedemann, Temperature Rise in a Battery Module with Constant Heat Generation, J. Electrochem. Soc. 142 (1995) 1054-1057. doi:10.1149/1.2044130.

[7] S. Al-Hallaj, J.R. Selman, Thermal modeling of secondary lithium batteries for electric vehicle/hybrid electric vehicle applications, J. Power Sources. 110 (2002) 341-348. doi:10.1016/S0378-7753(02)00196-9.

[8] T. I. Evans, R. E. White, A Thermal Analysis of a Spirally Wound Battery Using a Simple Mathematical Model, J. Electrochem. Soc. 136 (1989). doi:10.1149/1.2097230.

[9] E. Gümüşsu, Ö. Ekici, M. Köksal, 3-D CFD modeling and experimental testing of thermal behavior of a Li-Ion battery, Appl. Therm. Eng. 120 (2017) 484-495. doi:10.1016/j.applthermaleng.2017.04.017.

[10] H. Catherino, An Analysis of Heat Generation in a Lithium Ion Cell, SAE Soc. Automot. Eng. Trans. Catherino, H., “An Analysis of Heat Generation in a Lithium Ion Cell,” SAE Technical Paper 2015-01-2420, 2015 (2015). doi:10.4271/2015-01-2420.

[11] C. J. Willmott, K. Matsuura, Advantages of the Mean Absolute Error (MAE) over the Root Mean Square Error (RMSE) in Assessing Average Model Performance, Clim. Res. 30 (2005) 79. doi:10.3354/cr030079.

[12] T. Chai, R.R. Draxler, Root mean square error (RMSE) or mean absolute error (MAE)? - Arguments against avoiding RMSE in the literature, Geosci. Model Dev. 7 (2014) 1247-1250. doi:https://doi.org/10.5194/gmd-7-1247-2014.

[13] N.S. Spinner, R. Mazurick, A. Brandon, S.L. Rose-Pehrsson, S.G. Tuttle, Analytical, Numerical and Experimental Determination of Thermophysical Properties of Commercial 18650 LiCoO2 Lithium-Ion Battery, J. Electrochem. Soc. 162 (2015) A2789-A2795. doi:10.1149/2.0871514jes.

[14] A. Mills, S. Al-Hallaj, Simulation of passive thermal management system for lithium-ion battery packs, J. Power Sources. 141 (2005) 307-315. doi:10.1016/j.jpowsour.2004.09.025.

[15] S. Al Hallaj, H. Maleki, J.S. Hong, J.R. Selman, Thermal modeling and design considerations of lithium-ion batteries, J. Power Sources. 83 (1999) 1-8. doi:10.1016/S0378-7753(99)00178-0. 